\title{
Adopting Electronic Medical Record Systems and Health Monitoring Systems to Improve Health Care System in a National Cancer Institute
}

Aliyu Usman Ahmad ${ }^{*}$ and Ibrahim Alwawi ${ }^{2}$

${ }^{1}$ School of Engineering, University of Aberdeen, King's College, Aberdeen AB24 3FX, United Kingdom

${ }^{2}$ School of Computing Science and Digital Media, Robert Gordon University, Garthdee House, Garthdee Rd, Aberdeen AB10 7AQ, United Kingdom

\begin{abstract}
The appropriate use of state of the art technologies for health care service provision is of a great use and importance, not only for enhancing the patient's health care but also for facilitating, automating and streamlining patient's identification processes and record managements in the hospitals. According to the World Health Organization, hospitals nowadays are experiencing problems towards collecting, monitoring and management of health care data due to the fragmented structures and lack of regulation. In this study, the functioning and limitations of an existing healthcare software system were analysed with the development of an improved system to address the limitations. The study introduced the adaptation of both Electronic Medical Record System and Health Monitoring System, with the use of prototyping software development methodology; a justification for the chosen methodology is discussed. Among the critical elements of the health care systems analysed in this study includes schedule management, records management, patient care management and monitoring patient's medication with a detailed description of each phase of the prototyping development methodology.
\end{abstract}

\section{Background}

As clarified by Dean [1], a reliable Health care system should be able to provide an accurate, complete clinical decision supports, medical knowledge, alerts, communication as well as timely data to the healthcare organisation at all time. Numerous health care organisation currently run a risk of using incomplete health care systems, whose failure will result in a huge disaster that may potentially lead to the danger of losing lives. In this study, we critically reviewed and combined the functionalities of an Electronic Medical Record System (EMRS) and that of Health Monitoring Systems to come up with a fully automated Health Care Record systems. The proposed system will be developed to basically monitor and manage the hospital's health care records.

Managing healthcare records in the medical field is very crucial, researchers [2,3] described the significance of implementing the health monitoring system as a medium to ensure that health care providers are equipped with the necessary information needed to improve healthcare provision, reduce data fragmentation, as well as improving patient's safety.

The proposed system will be built with an ability to provide an accurate, complete clinical decision supports, medical knowledge, alerts, communication as well as timely data management to the hospital.

\section{Health Care Technologies}

Robert [4] points out the vital role of technology towards the provision of an effective healthcare service to patients; health care facility conveys a message to the hospital's patients, staffs, visitors, vendors and volunteers. The facility also communicates a flow of clues about the organisation and the medical care being provided there. The facilities convey caring, comfort, and compassion, commitment to patient well-being and safety, with a relieved stress for the hospital's staffs and healthcare experts. Some of the basic health care facilities include the clinical electric devices, clinical health facilities, and patient monitoring systems as well as the electronic medical records systems.
Furthermore, Robert [4] stated that the design of health care system is administered by many regulations and technical requirements as well as affected by many less defined needs and pressures. A well-designed health care system should be flexible, accessible, efficient, manageable, sustainable and secured. The proposed system was developed with the properties recommended by Robert [4] which entails a secured role management feature that enables the accessibility of functionalities of the system based on the user's role with the highly secured data management system.

\section{Information privacy in healthcare technologies}

The Information privacy and security in the healthcare sector is an issue of a great importance. In today's adoption of the digital patient records, there is a need for an increased regulation, provider consolidation, as well as the increasing need for information between patients, providers, and payers, for better information security.

There was a prediction by the International Records Management Trust [18] on the adoption of a universal electronic medical record (EMR) by entire health maintenance organisations (HMO) by the year 2019. Lucilla [5] clarifies that Healthcare information management systems are largely regarded as the single most important factor in improving healthcare quality and reducing related costs.

Evidence from recent years suggests a lack of adequate security measures has resulted in frequent data breaches that lead patients to be exposed to economic threats, mental anguish, and possible social stigma as stated by International Records Management Trust [18].

"Corresponding Author: Aliyu Usman Ahmad, School of Engineering, University of Aberdeen, King's College, Aberdeen AB24 3FX, United Kingdom; E-mail: r01aua14@abdn.ac.uk

Citation: Ahmad AU, Alwawi I (2017) Adopting Electronic Medical Record Systems and Health Monitoring Systems to Improve Health Care System in a National Cancer Institute. Int J Comput Softw Eng 2: 122. doi: https://doi. org/10.15344/2456-4451/2017/122

Copyright: (c) 2017 Ahmad et al. This is an open-access article distributed under the terms of the Creative Commons Attribution License, which permits unrestricted use, distribution, and reproduction in any medium, provided the original author and source are credited. 
Citation: Ahmad AU, Alwawi I (2017) Adopting Electronic Medical Record Systems and Health Monitoring Systems to Improve Health Care System in a National Cancer Institute. Int J Comput Softw Eng 2: 122. doi: https://doi.org/10.15344/2456-4451/2017/122

Page 2 of 9

Melissa [6] believed Privacy is an essential governing principle of the patient - physician relationship for effective healthcare delivery. Patients are required to share information with their physicians to facilitate correct diagnosis and determination of treatment, especially in other to prevent adverse drug interactions. However, patients may refuse to divulge important information in cases of health problems such as psychiatric behaviour and HIV as their disclosure may lead to social stigma and discrimination.

In view of the above, privacy measures were considered in the development of the proposed system. These includes restriction of data accessibility to only authorised users. Patient's records were also anonymised to ensure that only what is required is revealed to the health expert, and therefore concealing the patient's identity for the protection of privacy.

\section{Health Monitoring Systems (HMS)}

Health monitoring systems tracks and monitors the state of health of a patient with an ability to compile a chronological health history of the patient [2]. In the medical profession today as discussed by Romano [7], the advent of high technology has provided a countless of impressive diagnostic tools. However, these technologies focus on the diagnosis of acute conditions, as well as advanced warnings, preventive advice and routine check-ups for the effective patient's healthcare monitoring.

The need for an effective health monitoring is apparent in situations where the patient is:

1. In unstable physiological regulatory systems, for example in the case of a drug overdose or anaesthesia.

2. In a life-threatening condition, for example where there are indications of a heart attack.

3. In risk of developing a life-threatening condition. In a critical physiological state.

\section{Electronic Medical Record Systems (EMR)}

An Electronic Medical Record (EMR) system manages the patient's medical information created within a health organisation. As stated by [8] The patient's externally generated health records will be saved into the system as a word or PDF format and are somehow incorporated into the specified patient's record. It is essential to be able to process pre-existing electronic documents and as well extracts information to enable easy search and retrieval of records.

[9] justifies that Medical Record shall contain adequate and accurate information to ascertain the hospital's patients, support the diagnosis, justify the treatment, document the course and results, and stimulate continuity of care among health care providers. The introduction of decision support system (DSS) in drug management, test result and disease management provide weighty impact to clinical processes. Dean [1] states that alert flag and reminder provided by DSS in EMR can improve physician work and patient care. DSS also provides the audit trail for security distress that lists admissions and modifications by users to each patient's file with a record of the date and time. Therefore, the accessibility and modification of the patient's file can be traced easily.

\section{Health monitoring systems (HMS) and electronic medical records system (EMR)}

Health Monitoring Systems and the Electronic Medical Records Systems both play a significant role in the health sector. The health monitoring systems focused mainly on the integration of computerised data on each hospital patient, these includes (Patient's medications, clinical laboratory reports, allergies, diagnostics, etc.) with the provision of warning messages and suggestions regarding patient drug therapy. While the Electronic Medical Records systems focus mainly on the storage and management of the patient's medical information created within the health organisation.

\section{HMS and EMR systems similarities}

Based on the review conducted on the computer based, health information systems, both the systems have a common particular aim which is the "patient's healthcare" the systems are built mainly for the management, monitoring and securing the health organisation's health records. Both systems provide the health organisation with an ability to maintain their patient's healthcare effectively, the Electronic Medical Records focuses on the patient's health documents management while the health monitoring systems focus on the use of the stored data in order to monitor and maintain the well-being of the patient [16].

\section{HMS and EMR systems synthesis}

The use of both the Electronic Medical Records Systems and The Monitoring System in a health organisation will enhance the organisation's healthcare provision and provide the complete health record management and monitoring [17]. In order to enhance the functionalities and services of the current system, the authors will synthesise the health information systems in order to come up with an improve health system for the management and monitoring of health records within the health organisation.

In conclusion from the review of HMS and EMR, the following functions were derived from the essential features that will make up a system that satisfies the requirements of both HMS and EMR combined.

\section{Patient's medication Record \\ 2. Patient's Allergy records \\ 3. Laboratory Management \\ 4. Integrated communication Support \\ 5. Blood pressure monitoring \\ 6. Medication Notification \\ 7. Health record tracker \\ 8. Administrative Data management}

\section{Methodology}

The main challenge towards selecting and following a software development methodology is doing it wisely so as to provide a suitable process disciplines towards delivering the quality required for the system development success, while avoiding 
Citation: Ahmad AU, Alwawi I (2017) Adopting Electronic Medical Record Systems and Health Monitoring Systems to Improve Health Care System in a National Cancer Institute. Int J Comput Softw Eng 2: 122. doi: https://doi.org/10.15344/2456-4451/2017/122

Page 3 of 9

methodologies that waste time, consume productivity, depress developers, and misuse of project resources. Different types of the system development methodologies are used for the designing of the information system, depending upon the actual requirement of the system to be developed, as each and every methodology has its own strengths and weakness.

[10] described the system Development Methodology (SDM) as a framework that is used for the structuring, planning and controlling the process of the development of an information system. Different and wide ranges of system development methodologies have evolved over the years, each with its strengths and weaknesses. Each methodology is suitable to a specific project based on the project's organisational, technical as well as project team consideration. Therefore, one system development methodology may not be appropriate for all projects.

Based on the review conducted and the structure of the study, the selected methodology for carrying out the proposed study is the Prototyping methodology.

\section{Justification for selected methodology}

The authors selected the prototyping methodology for this paper because of the structure of the proposed system and the benefits of the methodology. Some of the reasons for selecting the prototyping methodology include;

1. It improves both the user participation during the system development and provides an effective communication among the project stakeholders. As a hospital monitoring system project implementation, the authors will require the participation of the users of the system being the medical experts of the hospital in order to prevent common errors during project development.
2. It helps the authors to easily identify confusing or difficult functions and missing functionalities.

3. It provides a quick implementation of the system.

4. It addresses the inability of many users to specify their information needs, and the difficulty of the system analyst to understand the user's environment, user involvement in system development will enable the analyst to clearly understand what the user really needs.

The project consists of wide range of users, interrelationships and functions, where project risk needs to be reduced and monitored throughout the development process.

\section{The Prototyping Methodology}

The prototyping methodology can be defined as an easily modified and extensible representation and simulation of a planned software system that includes its interface design and input/output functionality [11]. Highlighted the fact that Prototyping, been a new and continuously emerging methodology to software development, is one of the most interesting developments in the computer industry of the '90s. Prototyping becomes a recognisable alternative approach to the classical life cycle methodology.

The system prototype enables the users of the system to have an idea of how the system works and they may get new ideas for requirements and highlight the areas of strengths and weaknesses in the system, furthermore as the prototype is developed, it may reveal errors and omissions in the proposed requirements.

[12] stated that the system prototype is used during the system development process to carry out design experiments in order to check the system's feasibility. Prototypes can be used in order to reduce the time required for the development of user documentation.

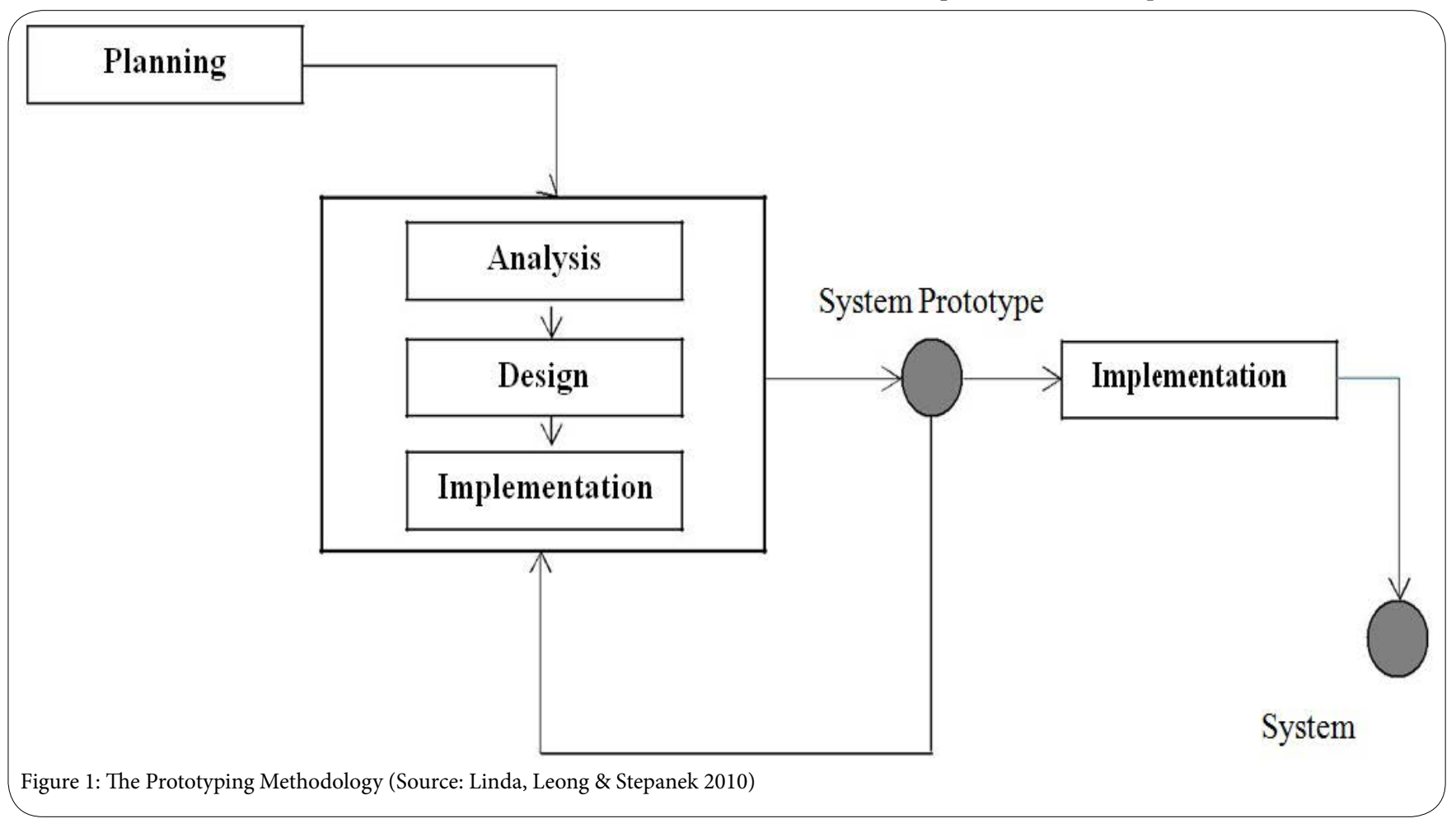


In a study of 39 prototyping projects, [13] highlights the benefits of using the prototyping methodology as:

1. Improved system design quality

2. Improved maintainability

3. Improved system usability

4. Reduced development effort

5. Reduced time wastage

6. A closer match of the system to user's needs

\section{Basic Principles of Prototyping}

1. The user is involved throughout the process; this will increase the chances of acceptance of the final implemented system, as the user already knew the system to be implemented.

2. The basic understanding of the organisational problem is necessary so as to avoid wasting time and resources in solving the wrong problem.

3. The methodology attempts to reduce project risk as it is divided into smaller segments and providing more flexibility during development.

4. It provides the ability to evolve from prototype to working system, providing the developers with ease in carrying out the processes.

\section{Planning phase}

This is the first phase in the prototyping methodology; it involves an analysis of the system's business needs, project scope, constraints, and system requirements. This is the phase in which the study's feasibility is analysed; the feasibility includes the technical feasibility. A comprehensive research upon the current technology was conducted in order to implement the proposed system to make sure it is suitable for the current environment in which it will be used.

Project work plan was developed in order to set out the project schedule that determines the processes and the project timing; the basic timing chart that was used is the Gantt chart. All risks associated with the proposed system were analysed in order to prevent project failure.

\section{Analysis Phase}

This is the phase in which the authors analysed the business process in terms of data flow and systems input and output. Part of the analysis entails the process of modelling the system behaviours. The analysis strategy of the study was developed in this phase, these includes the business process improvement and the business process reengineering.

Determining the business requirements was the basic task that was carried out in this phase as functions are expected to align with the business goals.

\section{Design}

This is the phase in which the system's components are designed. The phase involves the identification of interfaces and classes and their relationships. The physical system was designed in the phase, which includes all the interfaces and files within the system.

\section{Implementation}

This is the phase in which the system design is being transformed into a real-time system. The phase requires the use of a visual basic programming language as coding, debugging and testing is involved. Implementation is the last phase of the methodology as this is the phase in which final system development is completed and the post report of the study was compiled for future maintenance.

\section{System Analysis}

This section consists of the proposed system analysis; Analysis As defined by [14] is the detailed examination of the basics or structure of something, typically as a basis for discussion or interpretation. In this section, the authors carried out the requirement gathering analysis in order to come up with basic organisational needs and expectation of the proposed system. Furthermore, the authors analysed the conducted fact-finding techniques in order to come up with the overall system requirements.

\section{Requirement analysis strategy}

The requirement Analysis strategy is been developed in order to guide the authors towards creating a path for the requirement gathering process. The analysis that was carried out includes the analysis of the current system which is referred to as the analysis asis system and an analysis towards the way to develop an enhanced system which is referred to as the analysis to-be system.

The Business process improvement is one of the techniques in which the authors used in other to study the current business process of the organisation's system in order to come up with a way to design an improved system.

\section{Requirement gathering}

The requirement gathering is a method in which the authors has chosen to investigate the requirements of the system, the chosen gathering technique by the authors was the Interview and the Observation techniques. An interview was conducted by the Author with the National Cancer Institute (NCI) Hospital's Chief Medical Officer along with 4 other Nurses of the hospital. The Author made the interview during the hospital's office hours in the Medical officer's office.

The analysis of the output of the interview led the authors towards the development of a concept for the new system, the system concept will be used as a basis for the development of a set of business analysis models which describes how the new system will operate and the set of services it will provide to the organization.

\section{Analysis of as-is system}

Based on the research conducted and information gathered during the interview and observation methods on the functionality and services of the current system, the current NCI hospital's monitoring system is a windows application that has the following functions:

Register: This function enables the users of the system to register in order to obtain an id and password for accessing the system.

Login: The login function allows the system users to gain an access to their accounts in other to access the functions. 
Citation: Ahmad AU, Alwawi I (2017) Adopting Electronic Medical Record Systems and Health Monitoring Systems to Improve Health Care System in a National Cancer Institute. Int J Comput Softw Eng 2: 122. doi: https://doi.org/10.15344/2456-4451/2017/122

Page 5 of 9

Make an Appointment: This function provides the nurse with an ability to create an appointment between the patients and the doctors of the hospital.

View Appointments: The nurses use this function in other to view recently created appointments.

Edit Appointments: This function enables the nurses to make changes to an appointment that was saved in the system.

Delete Appointments: This function is used by the nurses of the hospital in other to cancel an appointment that was saved in the system.

Add New Patient: The function enables the nurses of the hospital to add new patients to the system.

Update patient record: The function enables the nurse to make changes to the details of the patient that was recently added.

The Nurse is responsible for the management and maintaining the system as all updates and modifications are carried out by the nurses of the hospital. The system is faced with the following problems;

Poor System performance: As observed by the authors, the system is slow, which makes it incapable of rendering the expected services at a suitable time. as complained by the hospital's medical staff. User control and navigations tend to be tedious for the system's users.

Low Level of Security: The system's inability to store patient's healthcare record results to the high risk of loss of health records and unauthorised access.

Lack of Enhanced Patient's Medication Monitoring: The current system does not store information about the medication schedules of the patients, which results in a poor healthcare provision by the nurses.

Inadequate Record Management Capabilities: The system does not store healthcare records, record storage and retrieval is not convenient for the hospital's staffs.

\section{System Implementation}

\section{Analysis of to-be system}

The to-be system is referred to as the new proposed system that was developed in other to overcome the current deficiencies of the current health monitoring system of the National Cancer Institute (NCI) hospital (As-is System). The system was built in other to maintain and manage the core medical activities of the hospital, by enhancing and improving the hospital's patient healthcare provision and effectiveness.

\begin{tabular}{|l|l|}
\hline ACTOR & DESCRIPTION \\
\hline Nurse & $\begin{array}{l}\text { The Nurse is a medical staff of the hospital } \\
\text { that uses the system to maintain the patient's } \\
\text { health records, appointment schedules as well as } \\
\text { medication management. }\end{array}$ \\
\hline Doctor & $\begin{array}{l}\text { This actor is a Medical staff of the hospital that } \\
\text { is responsible for medication prescription and } \\
\text { schedule in the system. }\end{array}$ \\
\hline Administrator & $\begin{array}{l}\text { This actor is responsible for maintaining the whole } \\
\text { system and users; he has the ability to Add, Update } \\
\text { as well as deletes users from the system. }\end{array}$ \\
\hline
\end{tabular}

Poor System Interface: The system interface is not user-friendly,

\section{System's actors definition}

The system's actors are referred to the users/system that is outside the system and interacts with the system. The (table 1) shows the system's actors and descriptions;

\section{Requirement definition}

[14] stated that the Requirements are classified into the System requirements which is referred to as the high-level abstract requirement that describes the services in which the system is expected to provide and constraints under which it is expected to operate and the User/Functional requirements which are referred to as the detailed description of what the system is been built to do.

\begin{tabular}{|c|c|c|}
\hline Requirement & Use Case (s) & Actor \\
\hline $\begin{array}{l}\text { 1. System should provide users with the } \\
\text { ability to } \log \text { in. }\end{array}$ & Login & $\begin{array}{l}\text { Administrator } \\
\text { Nurse } \\
\text { Doctors }\end{array}$ \\
\hline $\begin{array}{l}\text { 2. System should provide Nurse with } \\
\text { services to add a new patient. }\end{array}$ & \multirow[t]{4}{*}{$\begin{array}{l}\text { Manage } \\
\text { patient }\end{array}$} & \multirow[t]{4}{*}{ Nurse } \\
\hline $\begin{array}{l}\text { 3. System should provide Nurse with an } \\
\text { ability to update patient details. }\end{array}$ & & \\
\hline $\begin{array}{l}\text { 4. System should provide Nurse with the } \\
\text { ability to search for stored patients details. }\end{array}$ & & \\
\hline $\begin{array}{l}\text { 5. System should provide nurses with the } \\
\text { ability to manage patient's contacts. }\end{array}$ & & \\
\hline $\begin{array}{l}\text { 6. System should allow nurses to add } \\
\text { doctors } \\
\text { to the system. }\end{array}$ & \multirow[t]{2}{*}{$\begin{array}{l}\text { Manage } \\
\text { Doctors }\end{array}$} & \multirow[t]{2}{*}{ Nurse } \\
\hline $\begin{array}{l}\text { 7. System should provide nurses with the } \\
\text { ability to update doctor's details. }\end{array}$ & & \\
\hline $\begin{array}{l}\text { 8. System should provide nurses with the } \\
\text { ability to search for stored doctors. }\end{array}$ & & \\
\hline $\begin{array}{l}\text { 9. System should provide Nurse with the } \\
\text { ability to add new admission details. }\end{array}$ & \multirow[t]{3}{*}{$\begin{array}{l}\text { Manage } \\
\text { Admissions }\end{array}$} & \multirow[t]{3}{*}{ Nurse } \\
\hline $\begin{array}{l}\text { 10. System should provide Nurse with the } \\
\text { ability to update admission details. }\end{array}$ & & \\
\hline $\begin{array}{l}\text { 11. System should provide Nurse with the } \\
\text { ability to add diagnosis record. }\end{array}$ & & \\
\hline $\begin{array}{l}\text { 12. System should provide Nurse with an } \\
\text { ability to add medication schedule. }\end{array}$ & \multirow{3}{*}{$\begin{array}{l}\text { Manage } \\
\text { Medication } \\
\text { Schedule }\end{array}$} & \multirow[t]{3}{*}{ Nurse } \\
\hline $\begin{array}{l}\text { 13. System should provide Nurse with an } \\
\text { ability to update medication schedule. }\end{array}$ & & \\
\hline $\begin{array}{l}\text { 14. System should provide Nurses with an } \\
\text { ability to view the list of medication } \\
\text { schedules. }\end{array}$ & & \\
\hline $\begin{array}{l}\text { 15. System should provide Nurse with the } \\
\text { ability to add appointment schedules } \\
\text { between Patients and doctors. }\end{array}$ & \multirow[t]{2}{*}{$\begin{array}{l}\text { Manage } \\
\text { Appointment } \\
\text { Schedules. }\end{array}$} & \\
\hline $\begin{array}{l}\text { 16. System should allow Nurse to update } \\
\text { appointment schedules. }\end{array}$ & & \\
\hline $\begin{array}{l}\text { 17. System should provide Nurses with the } \\
\text { ability to view appointment schedules. }\end{array}$ & $\begin{array}{l}\text { View } \\
\text { Appointment } \\
\text { Schedule. }\end{array}$ & $\begin{array}{l}\text { Doctors } \\
\text { Nurses }\end{array}$ \\
\hline $\begin{array}{l}\text { 18. System should provide administrator } \\
\text { with } \\
\text { the ability to add users of the system. }\end{array}$ & \multirow[t]{3}{*}{ Manage User. } & \multirow[t]{3}{*}{ Administrator } \\
\hline $\begin{array}{l}\text { 19. System should allow administrator to } \\
\text { update users. }\end{array}$ & & \\
\hline $\begin{array}{l}\text { 20. System should allow administrator to } \\
\text { delete the user. }\end{array}$ & & \\
\hline
\end{tabular}

Int J Comput Softw Eng

ISSN: 2456-4451
IJCSE, an open access journal Volume 2. 2017. 122 
Citation: Ahmad AU, Alwawi I (2017) Adopting Electronic Medical Record Systems and Health Monitoring Systems to Improve Health Care System in a National Cancer Institute. Int J Comput Softw Eng 2: 122. doi: https://doi.org/10.15344/2456-4451/2017/122

Page 6 of 9

The software system requirements are been classified into the functional and non-functional requirements.

\section{User/Functional requirements}

The user/functional requirements consist of the statement of services the system should provide. The proposed system's user requirements are given in table 2.

\section{System/Non-functional requirements}

These are constraints on the services or functions in which the system is expected to provide. The project's Non-functional requirements are:

1. The system should display passwords in the star $\left(^{*}\right)$ format.

2. The system shall use a high level of security mode for the encryption \& decryption of passwords with the database.

3. The system shall restrict users based on their different level of privileges.

4. The system should send an SMS reminder to patients for appointments.

5. The system should make use of a centralised MySQL database for record storage and retrieval.

6. System interface should be simple for users to use.

7. The system should be designed with a language in which the user is familiar with.

8. The system should provide an easy health record tracking.

9. The system should login user within 30 seconds upon details validation.

10. The system should display confirmation messages when users attempt to cancel a process.

11. The system should display "Success" messages when a function is carried out successfully.
12. The system should be developed with error providers to specify invalid fields.

13. The system should use session to automatically save staff ID when records are added/rendered.

14. Error messages should specify the cause for an easy understanding and ease of usage.

15. The system should display confirmation messages when the user makes an update.

\section{Usability requirements}

International Standard Organization defined the usability of a product as the degree to which specific users can achieve a specific goal within a particular environment: effectively, comfortably, efficiently and in an acceptable manner. The project's usability requirements are;

1. The system will be used by the Medical staffs of the NCI (National cancer Institute) hospital.

2. All new users will be added and maintained by the system administrator.

3. The functions of the system will be categorised based on user privileges.

4. The system interface should be easy to use with ease of navigation.

5. The system should be able to respond to user input within a short period of time.

\section{System implementation}

The system implementation as the 4th stage of the prototyping methodology involves the transformation of the system design into a working system with the use of codes. The system implementation was carried out based on the defined requirements that were analysed by the authors in the previous phases of the prototyping methodology.

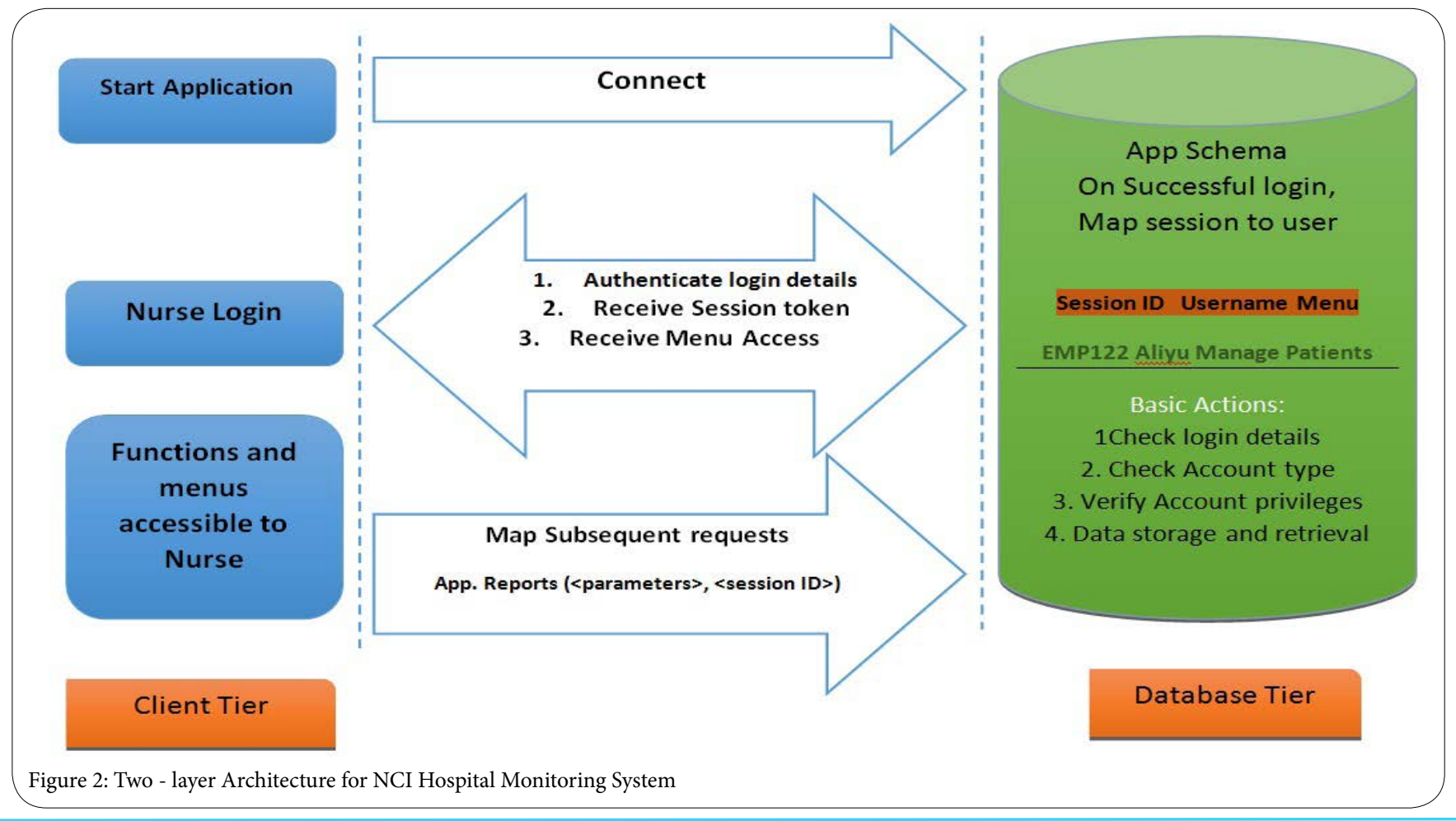


Citation: Ahmad AU, Alwawi I (2017) Adopting Electronic Medical Record Systems and Health Monitoring Systems to Improve Health Care System in a National Cancer Institute. Int J Comput Softw Eng 2: 122. doi: https://doi.org/10.15344/2456-4451/2017/122

Page 7 of 9

\section{Development environment}

The hardware and software tools are the basic platforms for the development of any kind of computer system. The authors conducted a comprehensive review before selecting the most appropriate tools for the project. Both the software and hardware development tools that were used for the project were chosen to be the most appropriate tools for the development of the Hospital Monitoring System.

\section{System architecture}

The system's architecture design defines the basic flow and process of handling data in the system with a description of the relationship between the various tiers in the system. Selecting the architecture depends on the type of software to be developed. The Hospital Monitoring System is developed based on the 2-tier architecture.

\section{Two tier software architectures}

Two-tier client/server architectures consist of 2 essential components;

\section{Client PC and the}

\section{Database Server}

The two-tier architecture allocates the system's user system interface entirely to the client. The architecture places database management on the server and breaches the processing management between client and server, resulting in the creation of two layers.

In the two-tier architecture, the client communicates with the server directly without an intermediate. The application program resides on the client while the database on the server. As shown in Figure 2.

As seen in figure 2 the system consists of two basic layers, which are the client tier and the database tier. The client tier is the basic application platform that enables the users of the system to interact with the system. The database tier, on the other hand, serves as the data storage medium in which all records about the system are stored. All transactions and requests by the users are to be carried out from the client tier; the client tier is responsible for accessing the database tier for transaction record storage, record retrieval as well as verification.

\section{Implementation of Graphical User Interface (GUI)}

Ambler [15] described the system interface as the platform in which the user of a system interacts through. The user interface plays a significant role towards the development of an information system as it serves as the medium to which the services of the system are provided.

As stated by [15] Implementing the system's user interface requires the need for a comprehensive review towards the selection of appropriate design structure, use of an appropriate colour combination as well as an easy and understandable user interface design. With regard to the Hospital monitoring systems, the term usability denotes not only the elegance and clarity with which the user interface of the system is designed but also how easy it is for the users of the system to accomplish the respective tasks.

In the design of the National Cancer Institute (NCI) Hospital Monitoring System, the authors deliberated the following design factors:
1. User-Friendly interface: A comprehensive observation was taken before the selection of the system's colour combinations. The colours are bright and hence not effective to the user's view. The system can be used for a very long time without affecting the user's sight.

2. System consistency: The interface design of the Hospital monitoring system is similar and consistent throughout, this makes it easier for the system's users to understand the functions clearly and navigate thoroughly without having to remember how to execute the functions.

3. Easy user control and flexibility: The authors used the hierarchical navigational structure for structuring the system's functions. This will enable the system users to access any function of the system at any point.

4. Improve user's Aid/Help tools: System users are provided with status messages throughout the process of the system and error providers and tooltips are designed to help the users in resolving errors when occurred.

\section{System testing}

The testing phase is one of the most significant phases in the whole of the project it is the phase in which a critical review and assessment of the system functionality were carried out. The phase involves evaluating the success or failure of the development procedures is reviewed to make sure the flow of the process goes as expected. There are different approaches to testing; from the conventional unit, integration and system testing. These usually constitute the validation phase while testing how the system affects or interacts with the users as per the product is the user acceptance test.

\section{Test plan}

The test plan was carried out to investigate the system's ability to provide the defined requirements in which it is built to provide. The authors, therefore, had to run a lot of unit tests during the process of implementing the system. The overall testing sessions did so far comprise of the unit test. The black box testing, the white box testing and the user acceptance testing.

\section{User acceptance testing}

The authors presented the system to a total number of 20 users, these users are mostly the medical staffs of the National Cancer Institute (NCI) hospital, and the evaluators had an average of 2 years of using computer health information system and are familiar with applications designed for handling health records.

The system's users were happy with the overall system interface design, as almost $80 \%$ evaluators rated the interface as excellent. This was inspiring as the good interface is essential for a successful design of a system, this will promote the system's usability and make it a userfriendly for the system users.

\begin{tabular}{|l|l|l|l|l|l|}
\hline Rating & Excellent & Very Good & Good & Poor & Very Poor \\
\hline Scale & 5 & 4 & 3 & 2 & 1 \\
\hline
\end{tabular}


Citation: Ahmad AU, Alwawi I (2017) Adopting Electronic Medical Record Systems and Health Monitoring Systems to Improve Health Care System in a National Cancer Institute. Int J Comput Softw Eng 2: 122. doi: https://doi.org/10.15344/2456-4451/2017/122

Page 8 of 9

Below is a table that represents the user's rating scale of the system;
\begin{tabular}{|c|c|c|}
\hline Evaluation Criteria & Average Scale /5 & Average Scale /100\% \\
\hline System Interface Design & 4.7 & $94 \%$ \\
\hline System's Flexibility & 4.4 & $88 \%$ \\
\hline User Friendly & 4.3 & $86 \%$ \\
\hline System Performance & 4.2 & $84 \%$ \\
\hline System benefits & 4.6 & $92 \%$ \\
\hline System's Consistency & 4.8 & $94 \%$ \\
\hline System's Security & 4.2 & $86 \%$ \\
\hline System's Functionalities & & \\
\hline Table 4: User Evaluation Rating & & \\
\hline
\end{tabular}

Below is a graph that represents the user's feedbacks on the system;

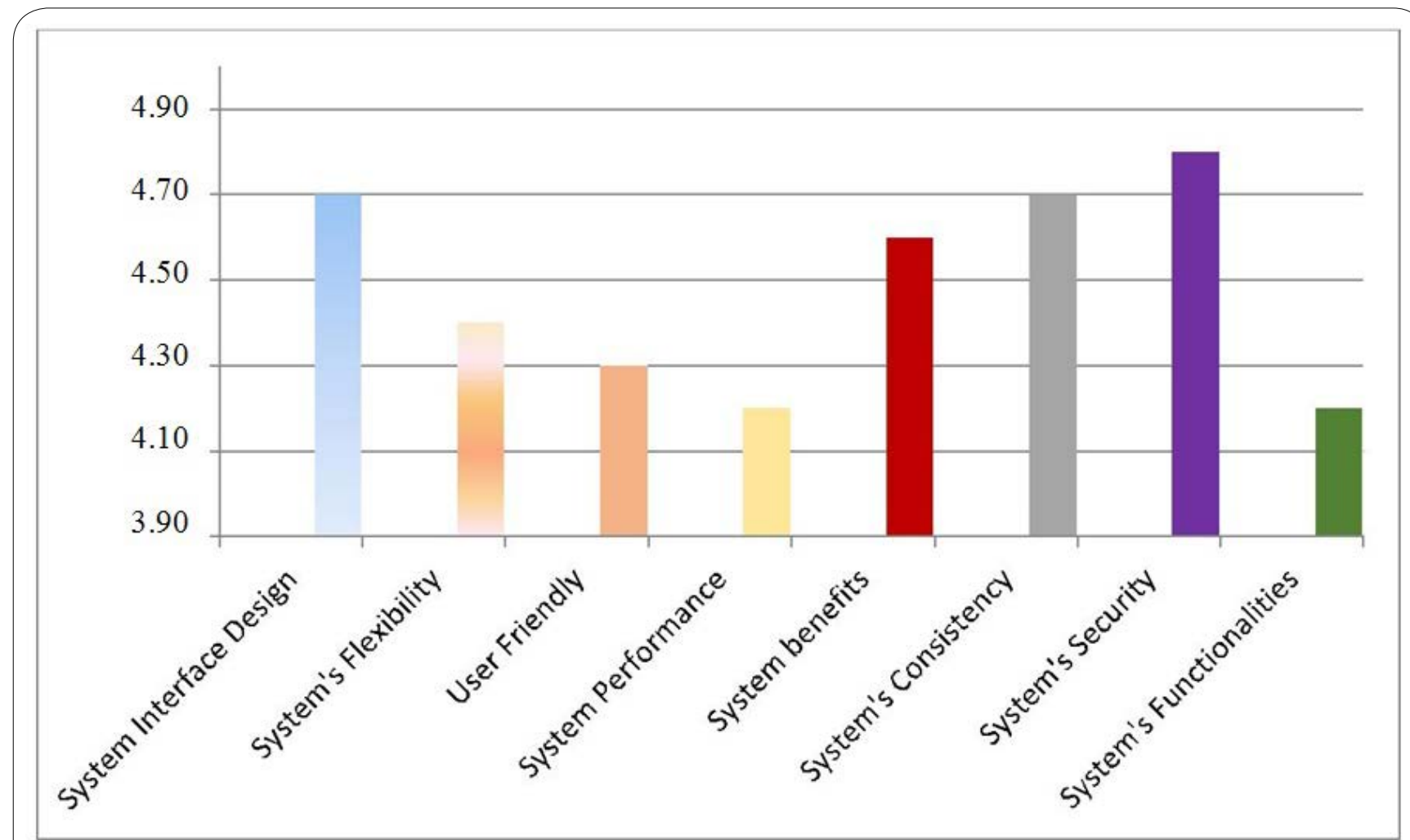

Figure 3: Bar chart representation of User Evaluation Rating scale

The above analysis clearly indicates that the users are generally satisfied with the system. The users' rating was satisfactory and the final overall corrections will be carried out before the final product is produced.

\section{Conclusion}

In this study, we analysed the functionality of an existing health care system and proposed an improved system by adopting the Electronic Medical Record and Health Monitoring systems with the use of the prototyping software development methodology, we have demonstrated the use of the prototyping methodology for a full development cycle of the software application. A comprehensive research on the supporting theories that are relevant to EMR and HM systems were discussed with a comprehensive review and comparisons of the systems along with the existing system in other to come up with an enhanced and superior system. The proposed system has shown a significant user satisfactory according to the user acceptance testing results presented. The selection of the chosen methodology was justified with supporting evidence on the advantages of the methodology.

\section{Competing Interests}

The authors declare that they have no competing interests.

\section{References}

1. Sittig DF, Teich JM, Osheroff JA, Singh H (2009) Improving Clinical Quality Indicators through Electronic Health Records: It Takes More than Just a Reminder. National Institutes of Health journal 124: 375-377.

2. Wager KA, Lee FW, Glaser JP (2009) Health Care Information Systems John Wiley and Sons Publishers, South Carolina. 
Citation: Ahmad AU, Alwawi I (2017) Adopting Electronic Medical Record Systems and Health Monitoring Systems to Improve Health Care System in a National Cancer Institute. Int J Comput Softw Eng 2: 122. doi: https://doi.org/10.15344/2456-4451/2017/122

Page 9 of 9

12. Skolnik NS (2010) Electronic Medical Records: A Practical Guide for Primary Care, Springer Publishers, Los Angeles.

13. Robert $F$ (2016) Health Care Facilities

14. Ohno-Machado $L$ (2011) Electronic health records and computer-based clinical decision support: are we there yet? J Am Med Inform Assoc 18: 109

15. Steward M (2005) Electronic Medical Records: privacy, confidentiality and liability', The Journal of Legal Medicine 26: 491-506.

16. Romano MJ, Stafford RS (2011) Electronic Health Records and Clinical Decision Support Systems: Impact on National Ambulatory Care Quality. Arch Intern Med 171: 897-903

17. Bleich HL, Slack WV (2010) Reflections on electronic medical records. International Journal of Medical Informatics 79: 1-4.

18. Cimino JJ, Teich JM, Patel VL (1999) What is Wrong with EMR?. Pane proposal for AMIA, 99.

19. Kothari CR (2008) Research methodology: Methods and techniques, New Age International Publishers, Delhi.

20. Linda G, Leong M, Stepanek J (2010) Teaching by Design, Corwin Press, United States of America

21. Sommerville I, Stevens P (2007) Software Engineering: Using UML: Software Engineering with Objects and Components, Pearson Publishers, California.

22. Gordon S, Bieman J (2016) Rapid Prototyping: Lessons Learned

23. Bennett S, McRobb S, Farmer R (2002) Object-Oriented Systems Analysis and Design Using UML, McGraw-Hill Publishers, Berkshire.

24. Ambler W, Scott I (2010) User Interface Design Tips, Techniques, and Principles

25. Ganju KK, Atasoy H, Pavlou PA (2016) Does the Adoption of Electronic Medical Record Systems Inflate Medicare Reimbursements? Available at SSRN.

26. Raymond L, Paré G, Ortiz de Guinea A, Poba-Nzaou P, Trudel MC, et al. (2015) Improving performance in medical practices through the extended use of electronic medical record systems: a survey of Canadian family physicians. BMC medical informatics and decision making 15: 27

27. Roper M, Millar L (1999) Managing electronic records. United Kingdom International Records Management Trust and International Council on Archives. 